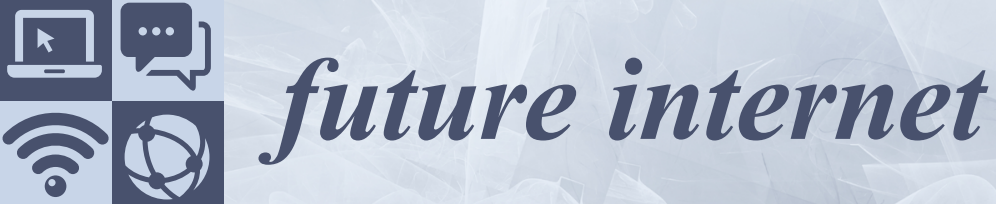

an Open Access Journal by MDPI

Tracked for

Impact

Factor
CITESCORE

5.4 


\section{future internet}

an Open Access Journal by MDPI

Editor-in-Chief

Prof. Dr. Dino Giuli
Message from the Editor-in-Chief

You are invited to contribute a research article or a comprehensive review for consideration and publication in Future Internet (ISSN 1999-5903). Future Internet is an international, peer-reviewed, open access journal, which provides an advanced forum for scientific studies related to Internet technologies and the information society.

Future Internet is published in open access format research articles, reviews and other contents are released on the Internet immediately after acceptance. The scientific community and the public have unlimited and free access to the content as soon as it is published.

We would be pleased to welcomeyou as one of our authors.

\section{Author Benefits}

Open Access Unlimited and free access for readers

C No Copyright Constraints Retain copyright of your work and free use of your article

$\&$ Thorough Peer-Review

S Discounts on Article Processing Charges (APC) If you belong to an institute that participates with the MDPI Institutional Open Access Program

【] No Space Constraints, No Extra Space or Color Charges No restriction on the length of the papers, number of figures or colors

ClO Coverage by Leading Indexing Services Scopus, ESCI (Web of Science), Ei Compendex, dblp, Inspec, and many other databases 


\section{Aims and Scope}

Future Internet (ISSN 1999-5903) publishes regular research papers, reviews and short communications. Our aim is to encourage scientists to publish their experimental and theoretical results in as much detail as possible. Therefore, there is no restriction on the length of the papers. The full experimental details must be provided so that the results can be reproduced.

The scope of Future Internet includes:

Internet-related topics, including web and mobile applications

Information society

Big data

Augmented reality

Smart cities

Cloud based computing

The internet of things

Semantic web, markup, RDF

Web services

Virtual and mirror worlds

e-Government

e-Education and e-Learning

Human and social factors

Quality of experience and living labs

Any emerging topics

\section{Editorial Office}

Future Internet Editorial Office futureinternet@mdpi.com MDPI, St. Alban-Anlage 66 4052 Basel, Switzerland Tel: +41616837734 www.mdpi.com mdpi.com/journal/futureinternet 
MDPI is a member of

\section{GASPA}

The Association of

Learned \& Profession

Society Publishers

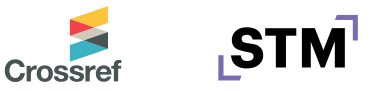

Society

for Scholarly

Publishing
$|\mathbf{C}| \mathbf{O}|\mathbf{P}| \mathbf{E}$

SPARC*

Europe

\section{DOAJ}

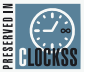

ORCID

\section{Follow}

f facebook.com/MDPIOpenAccessPublishing

twitter.com/MDPIOpenAccess

in linkedin.com/company/mdpi

(O) instagram.com/mdpiopenaccess

6 weibo.com/mdpicn

\%.) Wechat: MDPI-China

\section{Subscribe}

blog.mdpi.com 